\title{
Low Temperatures Lead to Higher Toxicity of the Fungicide Folpet to Larval Stages of Rana temporaria and Bufotes viridis
}

1 Christoph Leeb ${ }^{1 *}$, Laura Schuler ${ }^{1}$, Carsten A. Brühl' ${ }^{1}$, Kathrin Theissinger ${ }^{1,2}$

$2 \quad{ }^{1}$ iES Landau, Institute for Environmental Sciences, University of Koblenz-Landau, Landau, Germany

$3 \quad{ }^{2}$ LOEWE Centre for Translational Biodiversity Genomics, Senckenberg Biodiversity and Climate

4 Research Centre, Frankfurt, Germany

5

$6 *$ Correspondence:

7 Christoph Leeb

$8 \quad$ leeb@uni-landau.de

10 Short title: Temperature Dependent Toxicity of Folpet

12 Keywords: amphibia, climate change, green toad, common frog, pesticide, sensitivity, tadpole,

13 temperature effect

14 Number of words: 3,497

15 Number of figures: 1 


\section{Abstract}

18 Pesticides are one of the main drivers of the worldwide amphibian decline. Their actual toxicity

19 depends on a number of factors, like the species in focus or the developmental stage of exposed

20 individuals. As ectothermic species, the metabolism of amphibians is influenced by ambient

21 temperature. Therefore, temperature also affects metabolic rates and thus processes that might enhance

22 or reduce toxic effects. Studies about the interactive effect of temperature and toxicity on amphibians

23 are rare and deliver contrasting results. To investigate the temperature-dependent pesticide sensitivity

24 of larvae of two European species we conducted acute toxicity tests for the viticultural fungicide

25 Folpan® $500 \mathrm{SC}$ with the active ingredient folpet at different temperatures $\left(6^{\circ} \mathrm{C}, 11^{\circ} \mathrm{C}, 16^{\circ} \mathrm{C}, 21^{\circ} \mathrm{C}\right.$,

$2626^{\circ} \mathrm{C}$ ). Sensitivity of Rana temporaria and Bufotes viridis was highly affected by temperature: early

27 larvae (Gosner stage 20) were about twice more sensitive to Folpan® $500 \mathrm{SC}$ at $6^{\circ} \mathrm{C}$ compared to $21^{\circ} \mathrm{C}$.

28 Next to temperature, species and developmental stage of larvae had an effect on sensitivity. The most

29 sensitive individuals (early stages of $R$. temporaria at $6^{\circ} \mathrm{C}$ ) were 14.5 times more sensitive than the

30 least sensitive ones (early stages of $B$. viridis at $26^{\circ} \mathrm{C}$ ). Our results raise concerns about typical

31 ecotoxicological studies with amphibians that are often conducted at temperatures between $15^{\circ} \mathrm{C}$ and

$3220^{\circ} \mathrm{C}$. We suggest that future test designs should be performed at temperatures that reflect the

33 temperature range amphibians are exposed to in their natural habitats. Variations in the sensitivity due

34 to temperature should also be considered as an uncertainty factor in upcoming environmental risk

35 assessments for amphibians.

\section{Introduction}

37 To improve crop yields about 360 million $\mathrm{kg}$ of pesticide formulations are used per year on agricultural

38 fields in the European Union (data from 2017; Eurostat, 2020). Only a small part of these pesticides

39 reaches their target organism [2], and due to spray drift and run-off they can get into water bodies 
within or near agricultural fields $[3,4]$. Such agricultural ponds can be important breeding habitats for amphibians [5-7], which are therefore exposed to pesticides during their aquatic life stages. Pesticides were shown to have adverse effects on amphibians in several studies (e.g. [8-12], and are consequently identified as one of the main drivers in the global amphibian decline $[13,14]$. The actual toxicity of pesticides for amphibians depends on a number of factors, including the active ingredients [8], formulation additives $[9,10,15]$, the species in focus [12], a previous exposure to pesticides $[10,11]$ and the developmental stage $[10,12,16]$ of the tested individuals.

Also water temperature during pesticide exposure of larvae has an impact on the toxicity. Amphibians are ectothermic species and behavior and physiology are fundamentally influenced by environmental temperature [17]. Therefore, metabolic rates and thus processes that might enhance or reduce toxic effects, like the uptake of substances, the metabolic oxygen demand, and detoxification processes are temperature-dependent [18]. However, studies on the combined effects of temperature and pesticides on amphibians reveal contrasting results. Some observed that higher temperatures increased toxicity [19-21], while others showed a reduced toxic effect of pesticides on exposed amphibians [22-24]. For

Oligosoma polychroma, a skink (reptile) and thus also an ectothermic vertebrate species, even a heatseeking behavior was observed, that can be interpreted as response to increase the metabolism to better deal with stress after exposure to a glyphosate formulation [25].

Detailed knowledge of the relationship of pesticide sensitivity and temperature is central for two reasons. First, we are facing a global warming caused by climate change with more frequent temperature extremes [26]. Understanding the combined effect of this temperature increase and

60 pesticides will help to better estimate the impact of climate change on amphibian populations, to 61 identify potential threats on species and to set mitigation measures. Second, laboratory toxicity tests

62 for pesticides with amphibian larvae are typically performed at temperatures between $15^{\circ} \mathrm{C}$ and $20^{\circ} \mathrm{C}$ 63 (e.g. Mann et al., 2003; Johansson et al., 2006; Brühl et al., 2013; Wagner et al., 2017). These standard 
64 temperatures might not reflect the natural range of temperatures at which a species is exposed to

65 pesticides in its habitat. For example, larvae of Rana temporaria can be found in European ponds with

66 water temperatures only a few degrees above the freezing point [27]. In this study, the average water

67 temperature during the aquatic development was $9.7^{\circ} \mathrm{C}$ and the maximum temperature $23^{\circ} \mathrm{C}$ [27].

68 However, in small water bodies the maximum water temperatures might be above $30^{\circ} \mathrm{C}$, as even in

69 high-altitudes breeding ponds with temperatures of up to $26.5^{\circ} \mathrm{C}$ can be found [28]. Therefore, standard

70 laboratory toxicity tests might lead to the underestimation of possible sublethal or even lethal effects

71 that occur at lower or higher temperatures. Thus, knowing the temperature at which amphibians are

72 most sensitive will allow a more reliable assessment of the actual risk of pesticides.

73 In the present study, we conducted aquatic acute toxicity tests at temperatures between $6^{\circ} \mathrm{C}$ and $26^{\circ} \mathrm{C}$

74 to investigate the effect of the temperature on the sensitivity of amphibian larvae to the fungicide

75 Folpan® $500 \mathrm{SC}$ with the active ingredient folpet. With up to eight applications per growing season,

76 folpet is, next to sulfur, the most common fungicide in German vineyards and is preventively used to

77 protect plants primarily from mildew [29]. In general, fungicides are underrepresented in

78 ecotoxicological studies compared to other pesticide classes [30]. To identify potential species and

79 developmental stage specific differences in pesticide sensitivity, we tested early and late larval stages

80 of the common frog (Rana temporaria Linnaeus, 1758) and the green toad (Bufotes viridis Laurenti,

81 1768), two temperate species that can be found in breeding ponds in German vineyards [6]. Both

82 species are listed as "least concern" by the IUCN [31,32] and are widespread in Europe. $R$. temporaria

83 is discussed as a model organism for European amphibian species in toxicological studies [33]. This

84 species uses a variety of different water bodies for mating, which usually takes place in March, but can

85 start as early as the end of January [34] when water temperatures are above $5^{\circ} \mathrm{C}$ for some days $[34,35]$.

86 However, even at temperatures only a few degrees above freezing point spawning can be observed [36]

87 and early larvae can be found [27]. Preferred temperatures of early $R$. temporaria larvae from Germany 
are between $14.8^{\circ} \mathrm{C}$ and $19.6^{\circ} \mathrm{C}$, and between $16.5^{\circ} \mathrm{C}$ and $26.0^{\circ} \mathrm{C}$ of late larvae stages [37]. In contrast

to R. temporaria, B. viridis is considered to be a thermophile species with preferred spawning temperatures between $16^{\circ} \mathrm{C}$ and $20^{\circ} \mathrm{C}$. The optimum thermal tolerance limits for early larvae are between $12^{\circ} \mathrm{C}$ and $25^{\circ} \mathrm{C}$ [38].

92 The aim of the study was to get a better understanding about the temperature-dependent pesticide 93 sensitivity of two European amphibian species. We hypothesized 1) that the sensitivity of larvae to

94 Folpan ${ }^{\circledR} 500$ SC is highly affected by water temperature, 2) that early larvae are more sensitive than

95 late larval stages (see Adams and Brühl, 2020), and 3) that pesticide sensitivity differs between species.

\section{2. Material and methods}

\section{$97 \quad 2.1 \quad$ Sampling and animal husbandry}

Up to 300 eggs of eight and seven different clutches of $R$. temporaria and B. viridis, respectively, were

collected in March and May 2018. The spawning pond of R. temporaria is located in the Palatinate

Forest (Rhineland-Palatinate, Germany; 49.262433 N, 8.061896 E (WSG84), 242 m asl), distant from

any pesticide use. The pond of the $B$. viridis population is located in a vineyard dominated area

be expected to be contaminated with various pesticides. Eggs were transferred to glass aquaria (30 x

105 For logistical reasons, not all acute toxicity tests for the same developmental stage were conducted at

106 the same time. Therefore, parts of each clutch were kept at $10^{\circ} \mathrm{C}$ and daylight to slow down the

107 development of the eggs. After hatching, larvae were kept in groups of 50 individuals in aerated glass

108 aquaria filled with tap water at $21^{\circ} \mathrm{C}$. As the larvae grew, we reduced their density to 20 larvae per

109 aquaria. Cleaning of the aquaria and water renewal took place every second day. Larvae were fed daily

110 ad libitum with commercial fish food, cooked salad, and cucumber. 


\section{$111 \quad 2.2 \quad$ Test substance}

112 The fungicide Folpan® 500 SC (ADAMA Deutschland GmbH, Germany; purchased from a local

113 distributor) with the active ingredient folpet (38-42\% of weight; CAS number 133-07-03) was used for

114 all tests. Folpet is an organochlorine phthalimide with a molecular weight of $296.6 \mathrm{~g} / \mathrm{mol}$ and is used

115 as a protective, broad-spectrum fungicide against leaf spot diseases in grapevines. Data on

116 environmental contaminations are rare, but maximum measured concentrations of $50 \mathrm{ng} / \mathrm{L}$ in rivers

117 [39] and $4.53 \mu \mathrm{g} / \mathrm{L}$ in ponds [40] have been reported. To assess the environmental realistic toxicity

118 effect, the formulation was tested instead of the pure active ingredient. Other formulation ingredients

119 are "alkylnaphthalensulfonic acid, polymer with formaldehyde, sodium salt" (3.5-5\%), fumaric acid

$120(1-1.5 \%)$, methenamine $(0.5-1 \%)$ and 1,2 -Benzisothiazoline-3-one $(<0.1 \%)$. The acute aquatic toxicity

121 of the formulation leads to a 96-h $\mathrm{LC}_{50}$ of $0.256 \mathrm{mg}$ Folpan/L for the rainbow trout

122 (Oncorhynchus mykiss) [41].

\section{$123 \quad 2.3 \quad$ Experimental design}

124 Acute toxicity of Folpan® 500 SC was determined in a full-factorial design with different temperature

125 conditions and two developmental stages of both species. Early larval stages (Gosner stage 20; GS20;

126 first hatchling stage with external gill circulation; see Gosner (1960) for classification) were tested at

127 five different temperatures $\left(6^{\circ} \mathrm{C}, 11^{\circ} \mathrm{C}, 16^{\circ} \mathrm{C}, 21^{\circ} \mathrm{C}, 26^{\circ} \mathrm{C}\right)$. Late larval stages (Gosner stage $36-41$;

128 GS40; larvae with at least hindlimbs) were tested at three different temperatures $\left(6^{\circ} \mathrm{C}, 16^{\circ} \mathrm{C}, 26^{\circ} \mathrm{C}\right)$.

129 For each combination of temperature, species and developmental stage (=16 combinations in total), a

$13048 \mathrm{~h}$ static acute toxicity test was performed with six different pesticide concentrations, ranging

131 between 0 (control) and $4.2 \mathrm{mg}$ Folpan/L (see Supplementary Table 1). Fungicide concentrations were

132 chosen based on range-finding tests and previous studies with folpet $[16,43]$ to cover the concentration

133 range at which ideally $0-100 \%$ mortality of the test organisms should be observed. Range finding tests 
134 were performed as $48 \mathrm{~h}$ tests with three Folpan concentrations and a control group with three replicates

135 of one individual for each species/developmental stage and different temperatures. For each pesticide

136 concentration of the final acute toxicity test 25 (GS20) or 15 (GS40) individuals were used, resulting

137 in 150 and 90 individuals per test, respectively. Tests were conducted in $1.7 \mathrm{~L}$ glass jars containing $1 \mathrm{~L}$

138 FETAX medium [44] and the respective amount of Folpan® 500 SC. Before adding the folpet

139 formulation, the jars with the FETAX medium were cooled or heated to the test temperature in climate

140 chambers (WK 19'/+15-35, Weiss Technik GmbH, Reiskirchen, Germany; MLR-351H SANYO

141 Versatile Environmental Test Chamber, SANYO Electric Co. Ltd., Moriguchi, Japan). To reduce the

142 influence of thermal shock on the physiology of the animals, preselected larvae from different clutches

143 of about the same size and developmental stage (GS20 or GS40) showing normal behavior were placed

144 in plastic boxes and acclimated at least for one hour to the test temperature. Afterwards five (GS20) or

145 three (GS40) larvae were randomly placed in a test jar, resulting in five replicates/jars per pesticide

146 concentration. For each jar, the mortality of larvae was determined after $48 \mathrm{~h}$ of exposure, whereby

147 dead larvae were removed after $2 \mathrm{~h}$ and $24 \mathrm{~h}$ from the test jars. In accordance with the test guideline

148 for acute toxicity testing in fish (OECD test guideline No. 203, [45]), larvae were not fed during the

149 experimental period. Tests were performed in climate chambers set to the according test temperature

150 with a 16:8 day-night-rhythm.

\section{$\begin{array}{lll}151 & \mathbf{2 . 4} & \text { Statistical analysis }\end{array}$}

152 For each test the median lethal concentration causing 50\% mortality of test organisms ( $\mathrm{LC}_{50}$ value)

153 was determined using different concentration-response models (log-normal functions - LN.2, LN.3,

154 LN.4; log-logistic functions - LL.2, LL.3u, LL.4, LL.5; and Weibull-functions - W1.2, W1.3, W1.4,

155 W2.2, W2.3, W2.4) calculated with the R package "drc" [46]. To get the most accurate $\mathrm{LC}_{50}$ value, the

156 model that best describes the observed mortality of larvae was selected based on the lowest Akaike's

157 Information Criterion for each test. $\mathrm{LC}_{50}$ values between different test temperatures for the same 
158 species and development stage were compared by a confidence interval overlap test [47] with the

159 function "comped" implemented in "drc". As we hypothesised a correlation between temperature and 160 toxicity, we tested the $\mathrm{LC}_{50}$ of a species/developemental stage at a temperature only against the $\mathrm{LC}_{50}$

161 of the next higher temperature to reduce the probability of an alpha error accumulation. In case the

162 difference was not significant, we also tested against the two steps higher temperature. Confidence

163 interval overlap tests were also used to compare LC50 values between species and developement stages

164 at the same test temperature. For all comparisons, p-values were calculated following the method

165 described by Altman \& Bland [48]. When testing the same species and developmental stage at different

166 temperatures, or the same species or developemental stage at different temperatures, p-values were

167 adjusted with a Bonferroni correction. All statistical analyses were carried out in R (version 3.4.3; R

168 Core Team, 2019).

$169 \quad 2.5 \quad$ Animal welfare

170 The study was approved by the Landesuntersuchungsamt in Koblenz (Germany; approval number

171 G18-20-009), and the collection of clutches and the husbandry of larvae were permitted by the

172 "Struktur- und Genehmigungsdirektion Süd Referat 42 - Obere Naturschutzbehörde" (Neustadt an der

173 Weinstraße, Germany; approval number: 42/553-254/455-18). After the experiments all test organisms

174 were euthanized with a buffered $0.1 \%$ MS-222 solution.

\section{$1773 \quad$ Results}

178 The calculated $\mathrm{LC}_{50}$ values of Folpan® $500 \mathrm{SC}$ ranged between 0.30 and $2.90 \mathrm{mg}$ Folpan/L for $R$.

179 temporaria and 0.64 and $4.35 \mathrm{mg}$ Folpan/L for B. viridis (Table 1). Toxicity decreased (i.e. increasing 
180 LC $_{50}$ values) with increasing temperature for both tested species and developmental stages (see Fig. 1).

181 In particular, the $\mathrm{LC}_{50}$ of $\mathrm{GS} 20$ at $21^{\circ} \mathrm{C}$, the temperature at which toxicity tests are often conducted, 182 was 2 (R. temporaria) and 2.3 (B. viridis) times higher than the lowest observed $\mathrm{LC}_{50}$ value. A

183 temperature increase from $6^{\circ} \mathrm{C}$ to $16^{\circ} \mathrm{C}$ resulted in 1.7 to 2.0 and an increase from $16^{\circ} \mathrm{C}$ to $26^{\circ} \mathrm{C}$ in 1.2

184 to 3.8 times higher $\mathrm{LC}_{50}$ values. A temperature increase of $5^{\circ} \mathrm{C}(\mathrm{GS} 20)$ or $10^{\circ} \mathrm{C}(\mathrm{GS} 40)$ resulted always

185 in a significantly higher $\mathrm{LC}_{50}$ value (all $\mathrm{p} \leq 0.038$, see Table 1 ), except for the comparison of $6^{\circ} \mathrm{C}$ and

$18611^{\circ} \mathrm{C}$ in GS20 in both species and $11^{\circ} \mathrm{C}$ and $16^{\circ} \mathrm{C}$ in GS20 R. temporaria. In general, the most sensitive

187 individuals (R. temporaria GS20 at $6^{\circ} \mathrm{C}$ ) were 14.5 times more sensitive than the least sensitive ones

188 (B. viridis at GS20 $26^{\circ} \mathrm{C}$ ). Our analysis revealed that early larvae were more sensitive than late larvae,

with the expection of $B$. viridis at $26^{\circ} \mathrm{C}$ (Table 2). Comparing $\mathrm{LC}_{50}$ values between species showed

190 that $R$. temporaria is more sensitive in early and less sensitive in late developmental stages than $B$.

191 viridis (Table 3), suggesting an interaction between developmental stage and species. However, the

192 difference was not significant when comparing late developmental stages at $16^{\circ} \mathrm{C}$ and $26^{\circ} \mathrm{C}$ after a

193 Bonferroni correction. Across all temperature treatments in both developmental stages and species the

194 control and lowest concentration of $0.1 \mathrm{mg}$ Folpan/L did not lead to any mortality in tested larvae.

196 Figure 1: Calculated LC 50 values $( \pm 95 \% \mathrm{CI})$ of early (GS20) and late (GS40) developmental stages

197 of $R$. temporaria and B. viridis at different temperatures. For detailed values and differences between 198 temperatures see Table 1. 
201 Table 1: Calculated $\mathrm{LC}_{50}$ values for two developmental stages of $R$. temporaria and B. viridis at

202 different temperatures with 95\% confidence intervals and the used dose-response models. P-values

203 show results from confidence interval overlap tests when testing against the next higher temperature.

204 In case the difference was not significant, it was also tested against the two steps higher temperature.

205 Significant differences after Bonferroni-correction are presented in bold.

\begin{tabular}{|c|c|c|c|c|c|}
\hline $\begin{array}{l}\text { Developmental } \\
\text { stage }\end{array}$ & $\begin{array}{l}\mathbf{T} \\
\left({ }^{\circ} \mathbf{C}\right)\end{array}$ & Model & $\begin{array}{l}\text { LC }_{50} \\
(\text { mg Folpan/L) }\end{array}$ & $\begin{array}{l}95 \% \text { CI } \\
(\mathrm{mg} \mathrm{Folpan} / \mathrm{L})\end{array}$ & $\begin{array}{l}\text { p } \\
\text { (to next temperature) }\end{array}$ \\
\hline \multirow{5}{*}{ GS20 } & 6 & W2.2 & 0.30 & $0.28-0.31$ & $0.172\left(11^{\circ} \mathrm{C}\right) /<\mathbf{0 . 0 0 1}\left(16^{\circ} \mathrm{C}\right)$ \\
\hline & 11 & W2.2 & 0.39 & $0.29-0.49$ & $0.120\left(16^{\circ} \mathrm{C}\right) /<\mathbf{0 . 0 0 1}\left(21^{\circ} \mathrm{C}\right)$ \\
\hline & 16 & $\mathrm{~W} 2.2$ & 0.52 & $0.44-0.59$ & 0.001 \\
\hline & 21 & W2.2 & 0.68 & $0.66-0.70$ & $<0.001$ \\
\hline & 26 & $\mathrm{~W} 1.2$ & 1.12 & $1.10-1.15$ & - \\
\hline \multirow{3}{*}{ 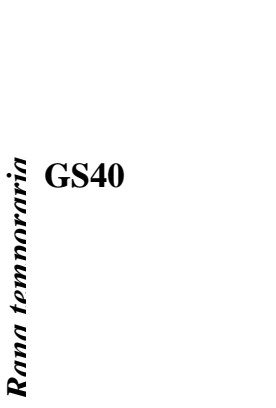 } & 6 & W2.2 & 1.29 & $1.22-1.36$ & $<0.001$ \\
\hline & 16 & W2.2 & 2.37 & $2.20-2.53$ & 0.004 \\
\hline & 26 & W2.2 & 2.90 & $2.79-3.00$ & - \\
\hline \multirow{2}{*}{ GS20 } & 6 & W2.2 & 0.64 & $0.57-0.71$ & $0.528\left(11^{\circ} \mathrm{C}\right) /<\mathbf{0 . 0 0 1}\left(16^{\circ} \mathrm{C}\right)$ \\
\hline & 11 & W2.2 & 0.69 & $0.61-0.76$ & $<0.001$ \\
\hline
\end{tabular}




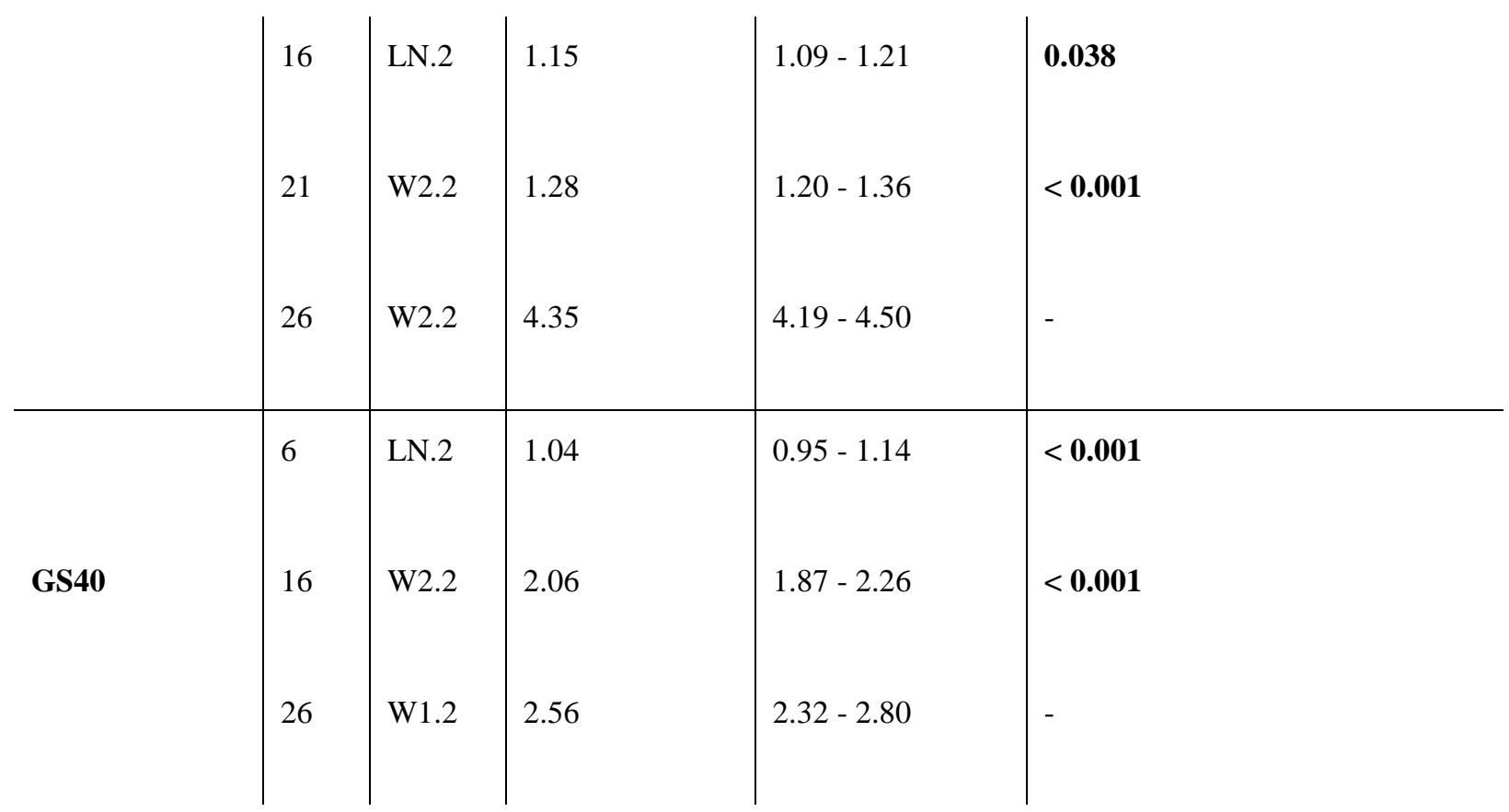

207 Table 2: Comparison of $\mathrm{LC}_{50}$ values between developmental stages. Significant differences after

208 Bonferroni-correction are presented in bold.

\begin{tabular}{l|l|l} 
Species & $\mathbf{T}\left({ }^{\circ} \mathbf{C}\right)$ & GS20 vs. GS40 \\
\hline R. temporaria & 16 & $<\mathbf{0 . 0 0 1}$ \\
& 6 & $<\mathbf{0 . 0 0 1}$ \\
\hline B. viridis & 26 & $<\mathbf{0 . 0 0 1}$ \\
& 16 & $<\mathbf{0 . 0 0 1}$ \\
& 6 & $<0.001$ \\
& 26 & $<\mathbf{0 . 0 0 1}$
\end{tabular}


210 Table 3: Comparison of $\mathrm{LC}_{50}$ values between species. Significant differences after Bonferroni-

211 correction are presented in bold.

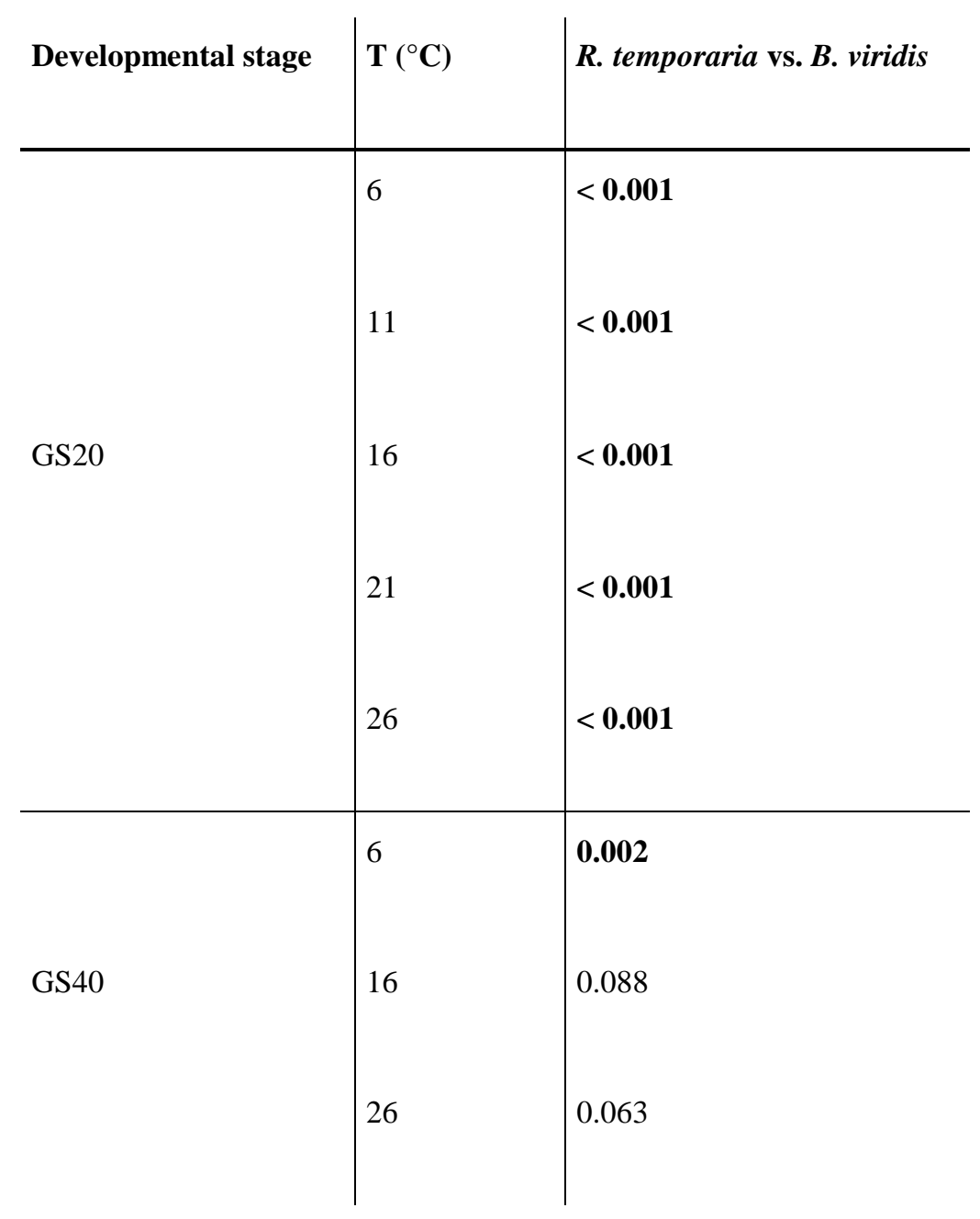

\section{Discussion}

215 In the present study, we demonstrated that the pesticide sensitivity of two European amphibian species

216 is highly affected by temperature, with individuals of both tested developmental stages and species

217 being more sensitive at lower temperatures. As we did not observe mortality at any temperature in

218 controls, the tested temperatures are within a range that allows survival. Therefore, observed mortalities 
219 are caused by Folpan® 500 SC, where the lethal concentration depends on the temperature.

220 Explanations for the relationship between temperature and sensitivity are diverse and depending on the

221 pesticide and organism in focus, but exact mechanisms often remain unknown. In our study, higher

222 temperatures might be nearer to the optimal temperature of the tested individuals, allowing effective

223 metabolism and detoxification. Likewise, low temperatures might be below the optimal temperature

224 range and result in additional stress, limiting the ability to cope with Folpan® 500 SC. Observed results

225 might also be caused by the characteristics of folpet, the active ingredient of the tested formulation

226 Folpan® 500 SC. In general, folpet degrades rapidly in aquatic environments and shows a half-life

227 (DT50) of $0.7 \mathrm{~h}$ at $25^{\circ} \mathrm{C}$ and $0.178 \mathrm{~h}$ at $40^{\circ} \mathrm{C}$ (both $\mathrm{pH} 7$; EFSA, 2009). Further, the degradation depends

228 on the $\mathrm{pH}$ of the medium $\left(\mathrm{DT} 50 \mathrm{pH} 4,25^{\circ} \mathrm{C}=6.5 \mathrm{~h}\right.$; DT50 $\mathrm{pH} 4,40^{\circ} \mathrm{C}=1.06 \mathrm{~h}$; DT50 ph $9,25^{\circ} \mathrm{C}$ and

$22940^{\circ} \mathrm{C}=$ too rapid to measure; EFSA, 2009). Thus, the alkaline FETAX medium (ranging between $\mathrm{pH}$

2307.7 and 8.29 in our study) even accelerates the degradation. Although information about the

231 degradation below $25^{\circ} \mathrm{C}$ is lacking, a temperature-dependent degradation that could have caused the

232 observed effects can be expected. Because of the overall fast degradation, no analysis of the actual

233 folpet concentration at the start and the end of a test was possible. It remains also unknown if the

234 degradation of the formulation Folpan ${ }^{\circledR} 500 \mathrm{SC}$ is similar to its active ingredient folpet, as additives

235 could increase the stability of the formulation. Additives might also influence the toxicity of the

236 formulation $[9,10,15,51]$. Regardless whether the lower sensitivity at higher temperatures is caused by

237 a more effective metabolism and detoxification, and thus reduced bioaccumulation, or by an increased

238 degeneration of folpet, Folpan® $500 \mathrm{SC}$ is more toxic for the two tested amphibian species at lower

239 temperatures.

240 Thus, increasing environmental temperatures might seem to have a positive effect on amphibians in

241 terms of a reduced folpet toxicity. However, climate warming will also cause a shift in the breeding

242 season to an earlier time of the year in temperate species [52]. Lötters et al. [53] showed that a shift of 
243 one month could decrease the glyphosate exposure risk during their migration to the breeding pond to

244 about $50 \%$ for $R$. temporaria. Thus, also the exposure risk of larvae might be reduced. However,

245 increased temperatures will also result in an earlier vegetation period of crops [54,55] and pesticides

246 might be applied earlier. Consequently, the general exposure risk, but also the temperature at which

247 amphibians will be exposed to pesticides in their aquatic habitats, will probably not change

248 fundamentally. However, also more frequent temperature extremes can be expected [26], resulting in

249 regional and temporary temperature drops so that also later larvae might be exposed to low

250 temperatures. Climate change will also cause more frequent pesticide applications [56,57], resulting in

251 higher overall pesticide loads in water bodies. Already today, many different pesticides can be found

252 in ponds within agriculture [58,59]. Although higher temperatures might result in a lower sensitivity

253 to folpet, contrary effects are possible for other pesticides and pesticide mixes. In vineyards, folpet is

254 usually applied first in late May [60], when $R$. temporaria larvae occur in late development stages. At

255 this time, B. viridis is still spawning and thus early larvae can be found. Only few data on actual

256 environmental contamination with folpet are available and data show that maximum measured

257 concentrations (50 ng/L [39]; $4.53 \mu \mathrm{g} / \mathrm{L},[40])$ are by a factor of at least 66 below the lowest $\mathrm{LC}_{50}$

258 values obtained in our study. We can therefore conclude that this pesticide will most likely not lethally

259 affect the two tested amphibian species at the larval stage, but sublethal effects cannot be excluded.

260 Thus, future studies should also focus on the effect of the temperature on sublethal endpoints like

261 development or behavior.

262 Our results are in contrast to most studies that investigated the effect of temperature on pesticide

263 toxicity for amphibian larvae in acute toxicity studies. In Materna et al. [20] leopard frog larvae

264 (Lithobates sp.; former R. pipiens complex) showed higher mortalities in 96-h acute toxicity tests for

265 the pyrethroid insecticide esfenvalerate at $22^{\circ} \mathrm{C}$ than at $18^{\circ} \mathrm{C}$. Boone and Bridges [19] found the same

266 relationship for $L$. clamitans (former $R$. clamitans) as the $96 \mathrm{~h}-\mathrm{LC}_{50}$ at $27^{\circ} \mathrm{C}$ was two times higher than 
267 at $17^{\circ} \mathrm{C}$. Lau et al. [21] calculated $96 \mathrm{~h}-\mathrm{LC}_{50}$ values for the pesticide methomyl for three Asian

268 amphibian species (Duttaphrynus melanostictus, Polypedates megacephalus, Microhyla pulchra) at

269 temperatures between $15^{\circ} \mathrm{C}$ and $35^{\circ} \mathrm{C}$, and observed lower $96 \mathrm{~h}-\mathrm{LC} 50$ values at higher temperatures.

270 However, Chiari et al. [24] showed that increased temperature can also reduce the toxicity of a pesticide

271 in 96-h acute toxicity tests by comparing published $\mathrm{LC}_{50}$ values for copper sulfate of various amphibian

272 species. In contrast to most 96-h tests, reduced toxic effects of pesticides at higher temperatures can

273 also be found in studies with tests running over several weeks or until metamorphosis. Baier et al. [23]

274 found that the effects of the glyphosate formulation Roundup® PowerFlex on mortality, growth and

275 tail deformation of the common toad (Bufo bufo) were more pronounced at $15^{\circ} \mathrm{C}$ than at $20^{\circ} \mathrm{C}$. In a 276 study on the glyphosate formulation Roundup® LB Plus, Baier et al. [22] also found increased effects

277 on the development of common toad larvae at lower temperatures $\left(15^{\circ} \mathrm{C}\right.$ compared to $\left.20^{\circ} \mathrm{C}\right)$ when

278 exposure occurred already as egg. Rohr et al. [61] reported that an increased temperature reduced the

279 time to the metamorphosis of larval Ambystoma barbouri exposed to the herbicide atrazine. Hence,

280 also the total exposure to atrazine was reduced in this study, which ameliorated increased adverse

281 effects of the pesticide [61].

282 With the exception of $B$. viridis at $26^{\circ} \mathrm{C}$, early larval stages were 1.6 to 4.5 times more sensitive than

283 late stages in both tested species. This is in line with the results from Adams and Brühl [16], where

284 early larvae of $R$. temporaria (Gosner stage 20) were two times more sensitive than late larvae (Gosner

285 stage 36) to the fungicide Folpan ${ }^{\circledR} 80$ WDG with the same active ingredient folpet. Also Wagner et

286 al. [10] found late larval stages of $R$. temporaria to be less sensitive in acute tests with two herbicides.

287 Interestingly, in our study early larvae of $\mathrm{B}$. viridis at $26^{\circ} \mathrm{C}$ were least sensitive. Bufotes viridis is a

288 thermophilic species, and the highest tested temperature is at the upper limit of its optimal thermal

289 range for development of early larvae $\left(12^{\circ} \mathrm{C}-25^{\circ} \mathrm{C}\right.$; Derakhshan and Nokhbatolfoghahai, 2015).

290 Hence, $26^{\circ} \mathrm{C}$ might allow optimal detoxification without causing temperature stress for early stages. In 
late larval stages additional stress caused by processes linked to metamorphosis could countervail the advantages of high temperatures, resulting in late larvae of $B$. viridis being more sensitive than early

larvae. Further, the optimal temperature of late $B$. viridis larvae could be even higher than $26^{\circ} \mathrm{C}$. This

294 might also explain why late larvae of $R$. temporaria (with assumed lower optimal temperature) were

295 less sensitive than $B$. viridis, although $R$. temporaria is more sensitive in early stages. In general,

species [12] and even population [10,11] specific differences in pesticide sensitivity are known. For

example, Adams et al. [43] showed that out of eight central European amphibian species, the most

sensitive species was five-times more sensitive than the least sensitive species towards the pesticide

folpet. Therefore, differences in the sensitivity in our study species are not surprising. However, the

original breeding pond where $B$. viridis eggs were obtained was situated within viticulture. Thus, it

cannot be ruled out that differences in the sensitivity are the result of an adaption of the population to

pesticides and not a species effect.

Folpet is, next to sulfur, the most common fungicide in German vineyards and thus understanding its

toxicity on non-target organisms is of high relevance. However, the fast and temperature dependent

degradation of folpet limits the conclusions drawn from our study. Thus, we recommend that future

studies on the relationship of temperature and sensitivity of amphibians should focus on pesticides with

a longer degradation time, not influenced as much by temperature. It might also be worth to consider

pesticide mixtures, as often several formulations are applied at the same time [60] and a mixture of

pesticides can be found in agricultural ponds [40]. It has recently been shown that the developmental

312 To date, no standard test guideline for acute toxicity tests of European amphibian species exists and

313 amphibians are also not explicitely considered in the environmntal risk assessment of pesticides. The

314 results of our study raise concerns about typical ecotoxicological studies with amphibians that are often 
315 conducted at temperatures between $15^{\circ} \mathrm{C}$ and $20^{\circ} \mathrm{C}$, because early larvae at $6^{\circ} \mathrm{C}$ were about two times

316 more sensitive to Folpan® $500 \mathrm{SC}$ as at $21^{\circ} \mathrm{C}$. Therefore, adverse effects in temperate amphibian

317 species might only be observed at lower or, depending on the tested pesticide, higher temperatures.

318 Based on the results we obtained in our study we conclude that an additional temperature related factor

319 needs to be incorporated in an uncertainty factor of an upcoming environmental risk assessments for

320 amphibians in the EU that reflects variations in pesticide sensitivity due to temperature. Additionally,

321 we agree with recommendations of previous studies [19,21-23] that future test protocols should

322 consider temperature as an important factor. Tests should be performed at temperatures that are

323 reflecting the temperature range amphibians are exposed to in their natural habitats, possibly also

324 including natural daily temperature fluctuations.

325

3265 Conflict of interest

327 The authors declare that the research was conducted in the absence of any commercial or financial

328 relationships that could be construed as a potential conflict of interest.

3296 Author contributions

330 CL, CB and KT conceived and designed the study. CL and LS performed the experiment. CL and LS

331 analyzed the data and drafted the manuscript. KT acquired the funding of the project and supervised

332 the work together with CB. All authors contributed to the writing process and approved the final 333 manuscript.

\section{$334 \quad 7 \quad$ Funding}

335 This project was financed by the Deutsche Forschungsgesellschaft (DFG-TH 1807-2). 


\section{Acknowledgments}

337 We want to thank Elena Adams, Haiying Xia, Cedric Abele and Jana Huhle for their help in the 338 laboratory.

\section{Data availability statement}

340 The original contributions presented in the study are included in the article/supplementary files, further

341 inquiries can be directed to the corresponding author/s.

\section{Literature}

344 1. Eurostat. Pesticide sales in the EU 2017 [Internet]. 2020 [cited 9 Feb 2020]. Available:

345 https://appsso.eurostat.ec.europa.eu/nui/show.do?query=BOOKMARK_DS-

346 382683_QID_1F97D137_UID_Z,1;\&zSelection=DS-382683UNIT,KG;DS382683INDICATORS,OBS_FLAG;\&rankName1=UNIT_1_2_-1_2\&

2. Pimentel D. Amounts of pesticides reaching target pests: Environmental impacts and ethics. J Agric Environ Ethics. 1995;8: 17-29. doi:10.1007/BF02286399 receiving water. Environ Pollut. Elsevier Ltd; 2018;234: 48-58. doi:10.1016/j.envpol.2017.11.032 
358 5. Knutson MG, Richardson WB, Reineke DM, Gray BR, Parmelee JR, Weick SE. Agricultural

359 ponds support amphibian populations. Ecol Appl. 2004;14: 669-684. doi:10.1890/02-5305

360 6. Lenhardt PP, Schäfer RB, Theissinger K, Brühl CA. An expert-based landscape permeability model for assessing the impact of agricultural management on amphibian migration. Basic Appl Ecol. Elsevier GmbH; 2013;14: 442-451. doi:10.1016/j.baae.2013.05.004

7. Berger G, Pfeffer H, Kalettka T. Amphibienschutz in kleingewässerreichen Ackerbaugebieten. Rangsdorf: Natur \& Text; 2011. temporaria) tadpoles. Environ Toxicol Chem. 2006;25: 3164. doi:10.1897/05-685R1.1

9. Mann R, Tyler M, Bidwell J. Toxicity of herbicide formulations to frogs and the implications for product registration: A case study from Western Australia. Appl Herpetol. 2003;1: 13-22. doi:10.1163/157075403766451199

10. Wagner N, Veith M, Lötters S, Viertel B. Population and life-stage-specific effects of two herbicide formulations on the aquatic development of European common frogs (Rana temporaria). Environ Toxicol Chem. 2017;36: 190-200. doi:10.1002/etc.3525

11. Hua J, Morehouse NI, Relyea R. Pesticide tolerance in amphibians: Induced tolerance in susceptible populations, constitutive tolerance in tolerant populations. Evol Appl. 2013;6: 
2860. doi:10.1002/etc.2379

13. Collins JP, Storfer A. Global amphibian declines: Sorting the hypotheses. Divers Distrib. 2003;9: 89-98. doi:10.1046/j.1472-4642.2003.00012.x

14. Hayes TB, Falso P, Gallipeau S, Stice M. The cause of global amphibian declines: a doi:10.1242/jeb.040865

15. Brühl CA, Schmidt T, Pieper S, Alscher A. Terrestrial pesticide exposure of amphibians: An underestimated cause of global decline? Sci Rep. 2013;3: 1135. doi:10.1038/srep01135

16. Adams E, Brühl CA. Fungicide Exposure Induces Sensitivity Differences in Aquatic Life Stages of European Common Frogs (Rana temporaria). J Herpetol. 2020;54: 331-336.

17. Wells KD. The ecology and behavior of amphibians. Chicago: The University of Chicago Press; 2007.

18. Honkanen JO, Kukkonen JVK. Environmental temperature changes uptake rate and doi:10.1670/19-004

19. Boone MD, Bridges CM. The effect of temperature on the potency of carbaryl for survival of tadpoles of the green frog (Rana clamitans). Environ Toxicol Chem. 1999;18: 1482-1484. 
doi:10.1002/etc.5620140409

21. Lau ETC, Karraker NE, Leung KMY. Temperature-dependent acute toxicity of methomyl pesticide on larvae of 3 Asian amphibian species. Environ Toxicol Chem. 2015;34: 2322-

22. Baier F, Jedinger M, Gruber E, Zaller JG. Temperature-Dependence of Glyphosate-Based Herbicide's Effects on Egg and Tadpole Growth of Common Toads. Front Environ Sci. 2016;4: 1-10. doi:10.3389/fenvs.2016.00051

23. Baier F, Gruber E, Hein T, Bondar-Kunze E, Ivanković M, Mentler A, et al. Non-target effects of a glyphosate-based herbicide on Common toad larvae (Bufo bufo, Amphibia) and associated algae are altered by temperature. PeerJ. 2016;4: e2641. doi:10.7717/peerj.2641

24. Chiari Y, Glaberman S, Serén N, Carretero MA, Capellini I. Phylogenetic signal in amphibian sensitivity to copper sulfate relative to experimental temperature. Ecol Appl. 2015;25: 596-

25. Carpenter JK, Monks JM, Nelson N. The effect of two glyphosate formulations on a small, 602. doi:10.1890/14-0439.1

26. IPCC. Climate Change 2013: The Physical Science Basis. Contribution of Working Group I to the Fifth Assessment Report of the Intergovernmental Panel on Climate Change. Stocker T., diurnal lizard (Oligosoma polychroma). Ecotoxicology. Springer US; 2016;25: 548-554. doi:10.1007/s 10646-016-1613-2 
28. Sztatecsny M, Gallauner A, Klotz L, Baierl A, Schabetsberger R. The presence of common frogs ( Rana temporaria ) increases the body condition of syntopic Alpine newts ( Ichthyosaura alpestris ) in oligotrophic high-altitude ponds : benefits of high-energy prey in a low-

29. Roßberg D, Ipach R. Erhebungen zur Anwendung von Pflanzenschutzmitteln im Weinbau. J für Kult. 2015;67: 410-416. doi:10.5073/JFK.2015.12.03

30. Zubrod JP, Bundschuh M, Arts G, Brühl CA, Imfeld G, Knäbel A, et al. Fungicides: An Overlooked Pesticide Class? Environ Sci Technol. 2019;53: 3347-3365. doi:10.1021/acs.est.8b04392

433 31. Kuzmin S, Ishchenko V, Tuniyev B, Beebee T, Andreone F, Nyström P, et al. Rana temporaria (European Common Frog). IUCN Red List Threat Species. 2009; e.T58734A86470817. doi:http://dx.doi.org/10.2305/IUCN.UK.2009.RLTS.T58734A11834246.en

32. Aghasyan A, Avci A, Tuniyev B, Crnobrnja-Isailovic J, Lymberakis P, Andrén C, et al. Bufotes viridis. IUCN Red List Threat Species. 2015; e.T155333A86444583. doi:http://dx.doi.org/10.2305/IUCN.UK.2015- 1.RLTS.T155333A74514442.en

440 33. Wagner N, Viertel B. Chapter 16. The Use of Aquatic Life-stages of European Amphibians in Toxicological Studies. In: Larramendy ML, editor. Ecotoxicology and Genotoxicology: Nontraditional Aquatic Models. Royal Society of Chemistry; 2017. pp. 371-406. 
doi:10.1039/9781782629887-00371

444 34. Günther R. Die Amphibien und Reptilien Deutschlands. Heidelberg: Spektrum Akademischer $445 \quad$ Verlag; 2009.

446 35. Muir AP, Biek R, Mable BK. Behavioural and physiological adaptations to low-temperature environments in the common frog, Rana temporaria. BMC Evol Biol. 2014;14: 1-11.

36. Loman J. Breeding phenology in Rana temporaria. Local variation is due to pond temperature and population size. Ecol Evol. 2016;6: 6202-6209. doi:10.1002/ece3.2356

37. Drakulić S, Feldhaar H, Lisičić D, Mioč M, Cizelj I, Seiler M, et al. Local differences of Zool Anz. 2017;268: 47-54. doi:10.1016/j.jcz.2017.04.005

38. Derakhshan Z, Nokhbatolfoghahai M. Thermal tolerance limits and effects of temperature on the growth and development of the green toad, Bufotes viridis. Salamandra. 2015;51: 129-136.

39. Konstantinou IK, Hela DG, Albanis TA. The status of pesticide pollution in surface waters (rivers and lakes) of Greece. Part I. Review on occurrence and levels. Environ Pollut.

40. Adams E, Leeb C, Brühl CA. Pesticide exposure affects reproductive capacity of common toads (Bufo bufo) in a viticultural landscape. Ecotoxicology. 2021;30: 213-223. 
464 42. Gosner KL. A Simplified Table for Staging Anuran Embryos Larvae with Notes on Identification. Herpetologica. 1960;16: 183-190. doi:10.2307/3890061

466 43. Adams E, Leeb C, Roodt AP, Brühl CA. Interspecific sensitivity of European amphibians

44. Dawson DA, Bantle JA. Development of a reconstituted water medium and preliminary validation of the Frog Embryo Teratogenesis Assay-Xenopus (FETAX). J Appl Toxicol.

45. OECD. Test No. 203: Fish, Acute Toxicity Test. OECD Guidelines for the Testing of 1987;7: 237-244. doi:10.1002/jat.2550070403

46. Ritz C, Baty F, Streibig JC, Gerhard D. Dose-Response Analysis Using R. PLoS One. 2015;10: e0146021. doi:10.1371/journal.pone.0146021

47. Wheeler MW, Park RM, Bailer AJ. Comparing median lethal concentration values using confidence interval overlap or ratio tests. Environ Toxicol Chem. 2006;25: 1441-1444. doi:10.1897/05-320R.1

48. Altman DG, Bland MJ. How to obtain the P value from a confidence interval. BMJ. 2011; 343:d2304. doi:10.1136/bmj.d2304

49. R Development Core Team. R: A language and environment for statistical computing. $\mathrm{R}$ Foundation for Statistical Computing. Vienna, Austria; 2020. doi:10.1111/j.13652621.1979.tb03829.x 
folpet. EFSA Sci Rep. 2009;297: 1-80.

486

487

488

489

490

491

492

494

495

496

497

498

499

500

501

502

503

504

51. Adams E, Gerstle V, Brühl CA. Dermal Fungicide Exposure at Realistic Field Rates Induces Lethal and Sublethal Effects on Juvenile European Common Frogs (Rana temporaria). Environ Toxicol Chem. 2021; etc.4972. doi:10.1002/etc.4972

52. Blaustein AR, Walls SC, Bancroft BA, Lawler JJ, Searle CL, Gervasi SS. Direct and indirect effects of climate change on amphibian populations. Diversity. 2010;2: 281-313. doi:10.3390/d2020281

53. Lötters S, Filz KJ, Wagner N, Schmidt BR, Emmerling C, Veith M. Hypothesizing if responses to climate change affect herbicide exposure risk for amphibians. Environ Sci Eur. 2014;26: 1-5. doi:10.1186/s12302-014-0031-4

54. Chmielewski FM, Müller A, Bruns E. Climate changes and trends in phenology of fruit trees and field crops in Germany, 1961-2000. Agric For Meteorol. 2004;121: 69-78. doi:10.1016/S0168-1923(03)00161-8

55. Lavalle C, Micale F, Houston TD, Camia A, Hiederer R, Lazar C, et al. Climate change in Europe. 3. Impact on agriculture and forestry. A review. Agron Sustain Dev. 2009;29: 433446. doi:10.1051/agro/2008068

56. Delcour I, Spanoghe P, Uyttendaele M. Literature review: Impact of climate change on pesticide use. Food Res Int. Elsevier Ltd; 2015;68: 7-15. doi:10.1016/j.foodres.2014.09.030

57. Olesen JE, Bindi M. Consequences of climate change for European agricultural productivity, land use and policy. Eur J Agron. 2002;16: 239-262. doi:10.1016/S1161-0301(02)00004-7

58. Bundschuh M, Elsaesser D, Stang C, Schulz R. Mitigation of fungicide pollution in detention 
ponds and vegetated ditches within a vine-growing area in Germany. Ecol Eng. Elsevier B.V.; 2016;89: 121-130. doi:10.1016/j.ecoleng.2015.12.015

508 59. Allinson G, Zhang P, Bui AD, Allinson M, Rose G, Marshall S, et al. Pesticide and trace metal 509 occurrence and aquatic benchmark exceedances in surface waters and sediments of urban

510 wetlands and retention ponds in Melbourne, Australia. Environ Sci Pollut Res. 2015;22: 10214-10226. doi:10.1007/s11356-015-4206-3

512 60. Leeb C, Brühl C, Theissinger K. Potential pesticide exposure during the post-breeding

513 migration of the common toad (Bufo bufo) in a vineyard dominated landscape. Sci Total

514 Environ. 2020;706: 134430. doi:10.1016/j.scitotenv.2019.134430

515 61. Rohr JR, Sesterhenn TM, Stieha C. Will climate change reduce the effects of a pesticide on 516 amphibians?: Partitioning effects on exposure and susceptibility to contaminants. Glob Chang 517 Biol. 2011;17: 657-666. doi:10.1111/j.1365-2486.2010.02301.x 


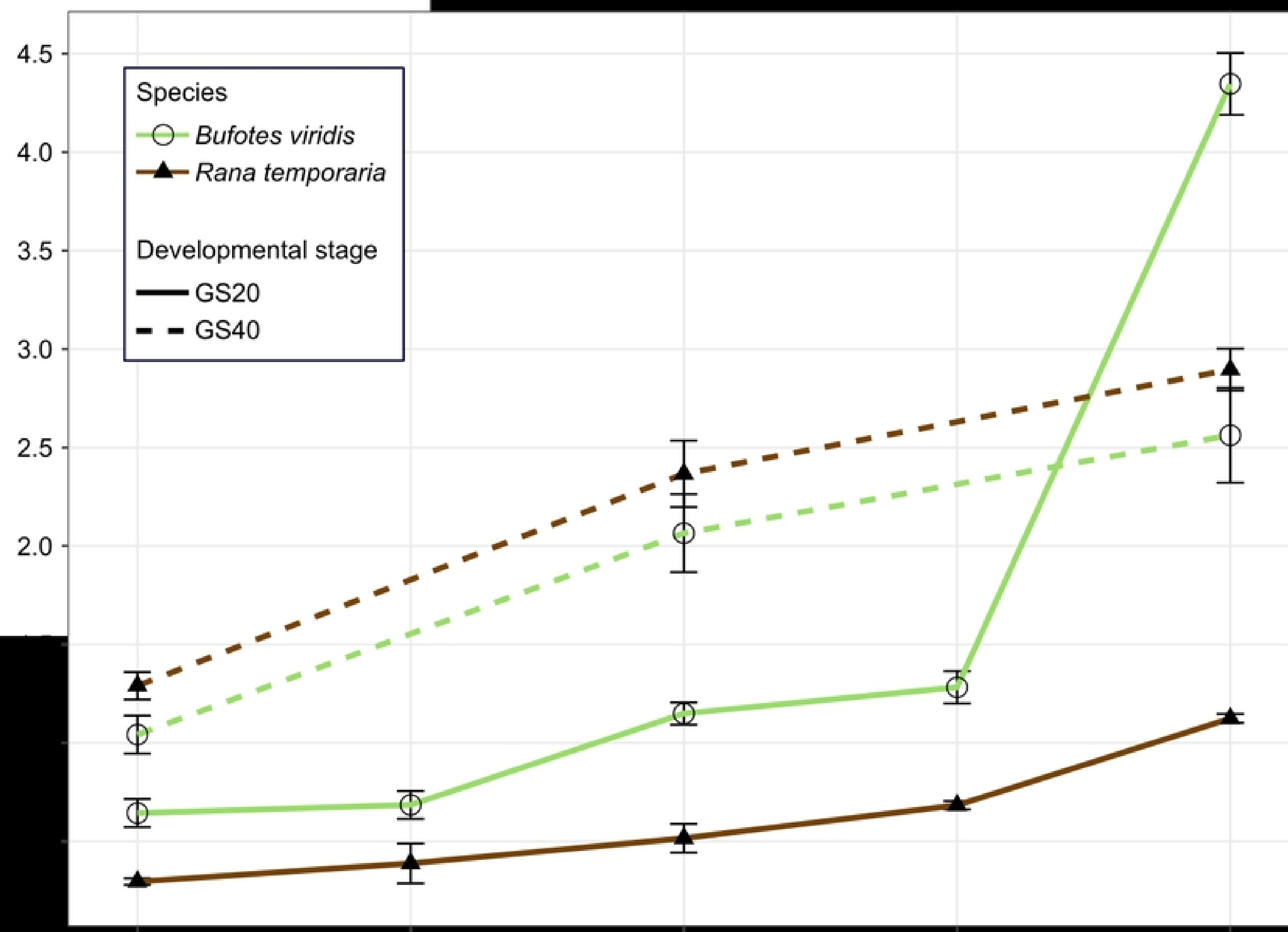

Figure 1 